University of Nebraska - Lincoln

DigitalCommons@University of Nebraska - Lincoln

2004

\title{
Linking Wild and Captive Populations to Maximize Species Persistence: Optimal Translocation Strategies
}

Brigitte Tenhumberg

University of Nebraska - Lincoln, btenhumberg2@unl.edu

Andrew J. Tyre

University of Nebraska at Lincoln, atyre2@unl.edu

Katriona Shea

Pennsylvania State University, k-shea@psu.edu

Hugh P. Possingham

University of Queensland, h.possingham@uq.edu.au

Follow this and additional works at: https://digitalcommons.unl.edu/bioscifacpub

Part of the Life Sciences Commons

Tenhumberg, Brigitte; Tyre, Andrew J.; Shea, Katriona; and Possingham, Hugh P., "Linking Wild and Captive Populations to Maximize Species Persistence: Optimal Translocation Strategies" (2004). Faculty Publications in the Biological Sciences. 119.

https://digitalcommons.unl.edu/bioscifacpub/119

This Article is brought to you for free and open access by the Papers in the Biological Sciences at DigitalCommons@University of Nebraska - Lincoln. It has been accepted for inclusion in Faculty Publications in the Biological Sciences by an authorized administrator of DigitalCommons@University of Nebraska - Lincoln. 
Published in Conservation Biology 18:5 (October 2004), pp. 1304-1314; doi: 10.1111/j.1523-1739.2004.00246.x

Copyright $\odot 2004$ Society for Conservation Biology; published by Wiley-Blackwell. Used by permission.

Submitted June 3, 2003; revised \& accepted January 22, 2004; published online September 28, 2004.

\title{
Linking Wild and Captive Populations to Maximize Species Persistence: Optimal Translocation Strategies
}

\author{
Brigitte Tenhumberg, ${ }^{1}$ Andrew J. Tyre, ${ }^{1}$ Katriona Shea, ${ }^{2}$ and Hugh P. Possingham ${ }^{3}$
}

\author{
1. The University of Queensland, St. Lucia, QLD 4072, Australia \\ 2. Department of Biology, 208 Mueller Laboratory, \\ Pennsylvania State University, University Park, PA 16802, U.S.A. \\ 3. The Ecology Centre, Department of Mathematics, and School of Life Sciences, \\ The University of Queensland, St. Lucia, QLD 4072, Australia \\ Corresponding author - B. Tenhumberg. Current address: School of Natural Resource Sciences, 302 Biochemistry Hall, \\ University of Nebraska-Lincoln, Lincoln, NE 68583-0759, U.S.A., email btenhumberg2@unl.edu
}

\begin{abstract}
Captive breeding of animals is widely used to manage endangered species, frequently with the ambition of future reintroduction into the wild. Because this conservation measure is very expensive, we need to optimize decisions, such as when to capture wild animals or release captive-bred individuals into the wild. It is unlikely that one particular strategy will always work best; instead, we expect the best decision to depend on the number of individuals in the wild and in captivity. We constructed a first-order Markov-chain population model for two populations, one captive and one wild, and we used stochastic dynamic programming to identify optimal state-dependent strategies. The model recommends unique sequences of optimal management actions over several years. A robust rule of thumb for species that can increase faster in captivity than in the wild is to capture the entire wild population whenever the wild population is below a threshold size of 20 females. This rule applies even if the wild population is growing and under a broad range of different parameter values. Once a captive population is established, it should be maintained as a safety net and animals should be released only if the captive population is close to its carrying capacity. We illustrate the utility of this model by applying it to the Arabian oryx (Oryx leucoryx). The threshold for capturing the entire Arabian oryx population in the wild is 36 females, and captive-bred individuals should not be released before the captive facilities are at least $85 \%$ full.

\section{Resumen}

La reproducción de animales en cautiverio es utilizada ampliamente para manejar especies en peligro, frecuentemente con la ambición de reintroducirlos al medio natural. Debido a que esta medida de conservación es muy costosa necesitamos optimizar decisiones, tales como cuando capturar animales silvestres o liberar individuos criados en cautiverio. Es poco probable que una estrategia particular siempre funcione mejor; más bien, esperamos que la mejor decisión dependa del número de individuos silvestres y en cautiverio. Construimos un modelo poblacional de cadena de Markov de primer orden para dos poblaciones, una en cautiverio y otra silvestre, y usamos programación dinámica estocástica para identificar estrategias estado-dependientes óptimas. El modelo recomienda secuencias únicas de acciones de manejo óptimo durante varios años. Una regla básica robusta para especies que pueden incrementar más rápidamente en cautiverio que en su medio natural es la captura de toda la población silvestre, cuando ésta se encuentre debajo del umbral de 20 hembras. Esta regla aplica aun si la población silvestre está creciendo y bajo una amplia gama de valores de diferentes parámetros. Una vez que se establece una población en cautiverio, debe ser mantenida como una red de seguridad y los animales deben ser liberados solo si la población en cautiverio se aproxima a su capacidad de carga. Ilustramos la utilidad de este modelo aplicándolo al Oryx leucoryx. El umbral para la captura de toda la población silvestre de oryx es 36 hembras, y los individuos criados en cautiverio no deberán ser liberados antes de que las instalaciones de cautiverio estén llenas por lo menos al 85\%.
\end{abstract}

Keywords: captive breeding, endangered species, optimal management strategies, stochastic dynamic programing, translocation, especies en peligro, estrategias de manejo óptimo, programación dinámica estocástica, reproducción en cautiverio, translocación 


\section{Introduction}

Extinction rates of populations or entire species have reached catastrophic levels (MacPhee 1999). Conservation biologists aim to prevent species extinction in the wild where possible, usually by removing or mitigating probable threats such as habitat loss or fragmentation, invasive species, or poaching (Vitousek et al. 1996). In certain cases, however, in situ conservation efforts may be insufficient, and more extreme intervention is required to enhance the probability of species persistence. As a last resort, captive breeding may be advocated (Beck et al. 1994; Snyder et al. 1996), though it is very expensive (Balmford et al. 1996; Kleiman et al. 2000).

Translocation is an inherent part of any captive breeding program. A translocation is the deliberate human-mediated movement of organisms between populations. Such translocations include movement between wild populations, movement from wild to captive populations (capture or collection), and movement from captive to wild populations (reintroduction or release). Captive breeding involves translocating individuals, either to remove them from the threats they face in the wild, or, if captive breeding is successful, to attempt their reintroduction (Ebenhard 1995).

One of the key factors determining the success of reintroduction programs is the number of individuals released (Griffith et al. 1989; Veltman et al. 1996; Wolf et al. 1998). As a consequence, the guidelines of the World Conservation Union (IUCN) for translocations in general (IUCN 1987) and for reintroductions in particular (IUCN 1998) specifically call for the use of models "to specify the optimal number ... of individuals to be released ... to promote establishment of a viable population."

Several surveys of success rates for reintroduction programs (largely for mammals and birds) have been carried out (Griffith et al. 1989; Wolf et al. 1996, 1998; Fischer \& Lindenmayer 2000). All indicate that success rates are poor $(<50 \%$; Griffith et al. 1989; Beck et al. 1994) and search for factors that correlate with (and potentially cause) reintroduction success. These surveys suggest that major factors influencing success include the number of individuals released and the number of release attempts (Griffith et al. 1989; Veltman et al. 1996; Wolf et al. 1998).

In situations where decision makers are faced with choices under uncertainty, methods of decision analysis can be a useful tool in evaluating different courses of action (Raiffa 1968). Models of reintroductions and captive breeding programs have been developed with a variety of methods and for a variety of systems (e.g., Hearne \& Swart 1991; Akcakaya et al. 1995; Southgate \& Possing- ham 1995; Sarrazin \& Legendre 2000), but few use decision theory or can lay claim to being true optimization models (Lubow 1996). Exceptions include Lubow (1996), who examined translocations between two wild populations with similar demography; Haight et al. (2000), who focused on translocation strategies for scenarios when there are uncertainties in future biological and economic parameters; Maguire (1986), who used a decision tree to determine whether proponents and opponents of captive breeding recommended management consistent with their beliefs about the status of the population; and Kostreva et al. (1999), who developed one-period planning models for optimization of genetic variation (based on founder contributions) of relocated animals.

Here we used an optimization algorithm, stochastic dynamic programming (SDP), to identify translocation strategies between wild and captive populations (e.g., in zoos, captive breeding programs, protected areas) that maximize overall species persistence. We were particularly interested in generating broadly applicable rules of thumb to guide conservation biologists in minimizing the probability of extinction of an endangered species. We first developed a stochastic population dynamic model for translocations between wild and captive populations that relies on demographic parameters and predicts the numbers of individuals in both populations. We then applied the model and algorithm to a case study of the Arabian oryx (Oryx leucoryx).

\section{Models}

\section{Stochastic Population Model}

In our model we considered a captive population, $Z$, and a wild population, $W$. Each population was limited to a maximum size $K_{z}$ or $K_{w}$. These limits were required for the numerical solution of the problem (see below). The $K_{z}$ had a natural interpretation as a consequence of space restrictions in the captive facilities. It was tempting to associate $K_{w}$ with "carrying capacity" of the wild population arising from limited resources or habitat through ceiling-type density dependence. A better interpretation, however, was that $K_{w}-1$ is the largest population size explicitly considered. All larger population sizes were lumped into a single state, $K_{w}$. We discuss the accuracy of this approximation below.

We assumed that females always have the opportunity to mate regardless of male abundance, so we only tracked the number of females. We also ignored age structure, so the dynamics of the populations can be modeled as a first-order Markov chain. Let the number 
of females in a population at any given time be the state of the population; the transition matrix describes the probability that the population moves from one state to another in a single year.

The Markov-chain transition matrix describing the transition rates from population density time $(t)$ from $t$ to $t+1$ was $\mathbf{A}=\mathbf{L S}$, which is the matrix product of the recruitment matrix $\mathbf{L}$ and the survival matrix $\mathbf{S}$. This means that only surviving individuals have the opportunity to reproduce.

Each element of $\mathbf{S}, s_{i, j}$, is the probability of having $i$ surviving individuals at $t+1$, given $j$ individuals at time $t$, with $0 \leq i \leq K$ and $0 \leq j \leq K$. This is given by the binomial probability

$$
\begin{aligned}
& s_{i, j^{\prime}}=\left\{\left(\begin{array}{l}
j \\
i
\end{array}\right) \mu^{j-i}(1-\mu)^{i} \text { if } 0 \leq i \leq j\right. \\
& \text { otherwise, } s_{i, j^{\prime}}=0
\end{aligned}
$$

where $\mu$ is the annual death probability.

To construct the recruitment matrix $\mathbf{L}$, we first calculated the probability distribution of the number of female offspring born to a given number of adult females. We assumed that the sex ratio is constant with probability $f$ of giving birth to a female newborn. Females had between 0 and $i_{\max }$ newborns of both sexes that survived to recruitment. There is a probability distribution, $l_{\mathrm{i}}$, that a female has $i$ surviving newborns $\left(i=0, \ldots, i_{\max }\right)$. For the present, we assumed that $i_{\max }$ $=1, l_{1}=\lambda$, and $l_{0}=1-\lambda$. The derivation below will work with any discrete, finite distribution. Thus, the binomial probability, $b_{i, 1}$, that a female has $i$ female newborns is

$$
\begin{aligned}
& b_{i, 1}=\left\{\sum_{j=i}^{i_{\max }} l_{j}\left(\begin{array}{l}
j \\
i
\end{array}\right) f^{i}(1-f)^{j-1} \quad \text { if } 0 \leq i \leq i_{\max } ;\right. \\
& \text { otherwise, } b_{i, 1}=0
\end{aligned}
$$

The probability that $j$ females have $i$ newborns can be obtained recursively as follows:

$$
\begin{gathered}
b_{i, j}=\left\{\sum_{k=0}^{i} b_{k, j-1} b_{i-k, 1} \quad \text { for } i \leq j * i_{\max } ;\right. \\
\text { otherwise, } b_{i, j}=0
\end{gathered}
$$

At high population densities, reproduction is truncated by $K$ such that $\Sigma$ (female newborns + adult females) $<K$. This is the only place where density dependence enters the basic population model. Given $b_{i, j}$ one can calculate the elements of the recruitment matrix $\mathbf{L}, l_{m, n^{\prime}}$ as the probability that the population density changes from $n$ to $m$ due to reproduction as

$$
l_{m, n}= \begin{cases}b_{m-n, n} & \text { if } n \leq m<K \\ 1-\sum_{t=n}^{K-1} b_{i-n, n} & \text { if } m=K \\ 0 & \text { if } m<n \text { or } m>K\end{cases}
$$

Based on the Markov-chain transition matrices, we calculated an approximation of the per capita growth rate as the expected number of female replacements resulting from one female:

$$
r=\sum_{i=1}^{K} i A_{i, 1} \approx E\left(\frac{n_{t+1}}{n_{t}}\right)
$$

This expected growth rate is a good approximation for $n$ up to $90 \%$ of $K$. Above this point the actual expectation is slightly reduced because the population cannot grow above $K$.

\section{Stochastic Dynamic Programming (SDP) Algorithm}

The algorithm optimized management decisions involving captive breeding programs. We addressed the following general questions: (1) At what population size should a wildlife manager start breeding an endangered species in captivity? (2) How many individuals should we take out of the wild? (3) How many individuals should we release into the wild?

The SDP model has three states: the number of individuals in captivity $\left(n_{z}=0, \ldots, K_{z}\right)$, the number of individuals in the wild $\left(n_{w}=0, \ldots, K_{w}\right)$, and the time over which the management plan will be optimized $(t=$ $0, \ldots, T)$. The change in population size over time in both populations follows from Markov-chain population matrices for the wild population $\mathbf{A}_{\mathrm{w}}$ and the zoo population $\mathbf{A}_{\mathbf{z}}$. We assumed that the per capita growth rate of the captive population equals or exceeds that of the wild population.

At each time step a wildlife manager can either do nothing or transfer $n$ individuals from the wild into captivity (captures) or vice versa (releases). The maximum number of captures or releases depends on the current population sizes in captivity and in the wild. If we define releases as negative captures, the SDP model evaluates the consequences of all possible captures (decision variable $\left.d=-n_{z^{\prime}} \ldots, 0, \ldots, n_{w}\right)$. We set an objective function $V$ that gives a reward to the manager at the end of the time horizon $(t=T)$ that minimizes the probability that the wild population is extinct $\varepsilon$ years after the captive breeding programs ceases:

$$
V\left(T, n_{w^{\prime}} n_{z}\right)=1-a_{0, n_{w}}^{\prime},
$$

where $a_{i, j}{ }_{i, j}$ is an element of the transition matrix $\mathbf{A}_{\mathbf{w}}^{\varepsilon}$. In matrix models one can project populations into the 
future by raising the population matrix to the power of the number of future time steps. The $V$ minimizes the extinction probability $\varepsilon$ time steps in the future, thus rewarding solutions resulting in higher wild population sizes. We normally set $\varepsilon=128$ years. With some parameter settings, however, the wild population is virtually guaranteed to be extinct long before 128 years. In those cases we set $\varepsilon=32$. The value of $\varepsilon$ is a power of 2 to minimize the number of matrix multiplications by repeatedly squaring the matrix $(\mathbf{A A}=$ $\mathbf{A}^{2}, \mathbf{A}^{2} \mathbf{A}^{2}=\mathbf{A}^{4}$, and so on). Equation 6 represents one of many possible objective functions. Other possibilities are minimizing the cost of translocation strategies or simply having any number of wild individuals. Obviously, the optimal strategy depends on the objective function used.

Transferring individuals between captivity and the wild imposes certain biological costs on the populations. The SDP model considers the following costs in terms of decreased reproduction and increased mortality. (1) We assumed that, as a result of stress and disorientation, translocated individuals do not breed in the year of translocation. It is largely unknown whether newly translocated individuals may breed, so we assumed the worst-case scenario. (2) Only a fraction of wild individuals survive the transfer to captivity because individuals may die from injuries sustained during capture or from stress during transport. Similarly, not all individuals translocated from captivity to the wild survive. (3) In addition, there might be a cost to the wild population as a whole if captive breeding programs create an uncontrolled demand for live individuals and profiteers think they can sell them to zoos (Rabinowitz 1995; Struhsaker \& Siex 1998). We assumed that all aforementioned costs apply only to the first year following capture or release of animals. This implies that appropriate government actions against illegal hunting take effect within 1 year and that the genetic makeup between captive and wild animals is the same. The latter assumption might be violated for some species, particularly after long periods of captivity. Directionally selected traits important to survival, such as foraging ability, disease resistance, or predator avoidance, when released from selection, can decline as much as $2 \%$ due to an increased frequency of deleterious mutation (Shabalina et al. 1997; Reed \& Bryant 2001). Including long-term effects greatly increases the state space, however, and the magnitude of long-term effects is largely unknown for most species.

Mortality costs were modeled by means of the ratio $\alpha(\alpha=$ reduced survival/natural survival). The factors ranged from 1 to 0 , with lower values indicating higher costs. So the new mortality was $\mu_{\text {new }}=1-[(1-\mu) a]$. We calculated three additional Markov-chain matrices employing Equations 1-4 but using higher mortality rates for calculating $S: \mathbf{A}_{\text {rel }}$ for released individuals, $\mathbf{A}_{\text {capt }}$ for captured individuals, and $\mathbf{A}_{\text {fixed }}$ for the noncaptured individuals of the wild population. Stochastic dynamic programming operates by back-stepping from the terminal time (at which we receive reward $V$ ) to the present (Bellman 1957). The dynamic programming equation in this case was

$$
V\left(T, n_{w^{\prime}} n_{z}\right)=\max _{d} \begin{cases}\text { do nothing } & \text { if } d=0 \\ \text { release } & \text { if } d<0 \\ \text { capture } & \text { if } d>0\end{cases}
$$

where $d$ is the number of captured or translocated individuals (releases being considered negative captures), and

$$
\begin{aligned}
& \text { do nothing }=\sum_{i=0}^{K_{z}} \sum_{j=0}^{K_{w}} V(t+1, i, j) \times a_{j, n w}^{w} a_{i, n z}^{z} \text {, } \\
& \text { release } \quad=\varphi+\sum_{i=0}^{K_{z}} \sum_{j=0}^{K_{w}} \sum_{k=d}^{0} V(t+1, i, j-k) \\
& \times a_{j, n w}^{w} a_{-k,-d}^{r e l} a_{i, n_{z}+d}^{z} \text {, and } \\
& \text { capture } \quad=\varphi+\sum_{i=0}^{K_{z}} \sum_{j=0}^{K_{w}} \sum_{k=0}^{d} V(t+1, i+k, j) \\
& \times a_{j, n w-d}^{w-b} a_{k, d}^{c a p} a_{i, n z}^{z}
\end{aligned}
$$

Superscripts indicate the transition matrix (e.g., $a_{i, n z}^{z}$ is the probability that $n_{\mathrm{z}}$ females of the captive population in year $t$ become $i$ females in year $t+1$ ).

For some parameter combinations the optimization surface was very flat, resulting in virtually the same survival probabilities for a range of management strategies. If the benefit of transferring some individuals from captivity to the wild or vice versa is insignificant, it makes more sense to do nothing. Therefore, we introduced a small penalty, $\varphi$, for doing something, with $\varphi=10^{-12}$.

\section{Model Scenarios}

The SDP algorithm calculates the optimal decision for each combination of wild and captive population numbers at each time step. For example, if we consider population sizes of $0-50$ females in the wild and 0-20 females in captivity, the size of the decision matrix at each time step is 1071 (decision matrix, $\left[K_{w}+1\right] \times\left[K_{z}+1\right]=$ 1071). This complexity makes the interpretation of an extensive sensitivity analysis infeasible. Instead, we ran the model with a limited set of different parameter combinations. We changed one or two parameters at a time for either the wild or the captive population. The parameters of all scenarios are listed in Tables 1 and 2 . 


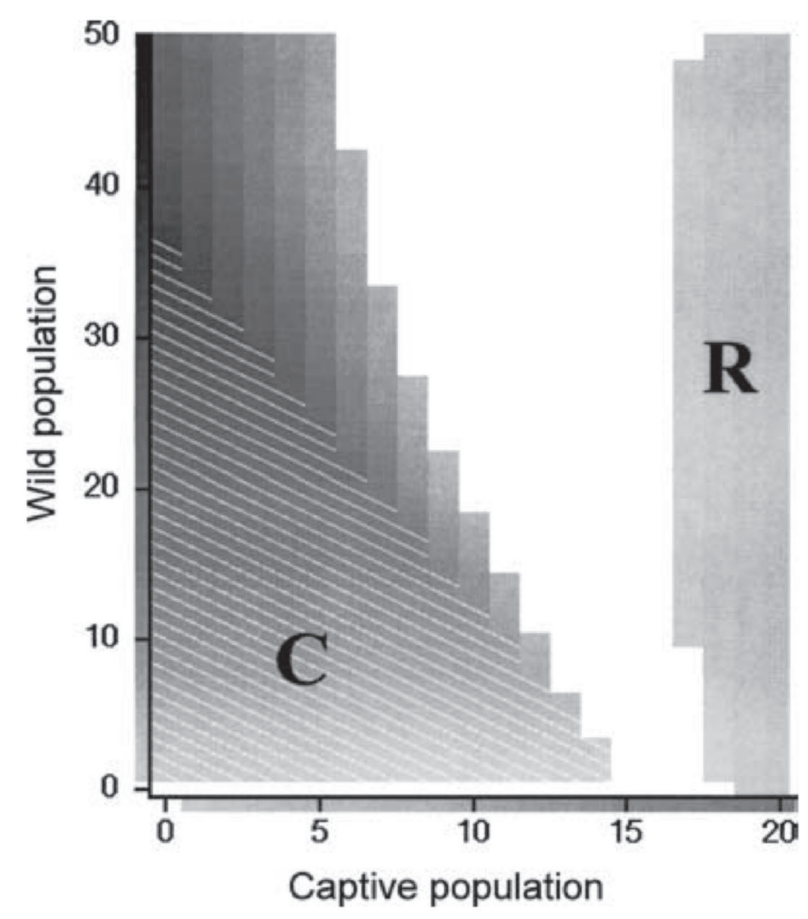

Figure 1. Optimal number of translocated animals as a function of population numbers in the wild and in captivity. The grayscale intensity is proportional to the number of translocated animals: white $=0$; dark gray $=50$. Key: $C$, captures; $R$, releases; stripes, entire wild population should be captured $(d$ $=n_{w}$ ) (captive population: $\lambda_{z}=1.0, \mu_{z}=0.1, r_{z}=1.3$; wild population: $\left.\lambda_{w}=0.8, \mu_{w}=0.4 ; r_{w}=0.85\right)$.

\section{Results}

We consider a maximum of $K_{w}=50$ females in the wild and $K_{z}=20$ females in captivity. The objective of the optimization algorithm was to minimize the extinction probability in the wild, so the entire captive population is released at the time horizon $(T=100)$. Here we only present stationary decisions, which means we stepped backward in time until the decisions were independent of the time remaining. This generally occurred by $T=70$. The results of the SDP algorithm are complex because they can be different for each combination of female numbers in the wild and in captivity. We present the entire decision matrix for two scenarios. For the remaining scenarios, we show only the boundaries between $d<0$ (start releasing animals), $d=0$ (doing nothing), and $d>0$ (stop capturing) (boundaries between the gray and white areas in Figure 1). If the population was growing faster in captivity than in the wild, the model suggested aiming for a large captive population, even if the wild population was growing. The particulars of the optimal strategy differed depending on the growth rates of the populations in the wild and in captivity. Changing the capturing mortality $\left(\alpha_{\text {capt }}\right)$, fixed mortality $\left(a_{\text {fixed }}\right)$, or release mortality $\left(a_{\text {rel }}\right)$ did not influence the optimal management strategy significantly (results not shown).
These population boundaries are rather small, but running the model with larger values of $K_{w}$ and $K_{z}$ was not feasible because the size of the population in the wild and in captivity determined the state space, and in SDP models the running time increases exponentially with the state space. For example, running the model with slightly larger maximum populations of $K_{w}=150$ and $K_{z}=30$ took $>9$ days on a $700 \mathrm{MHz}$ PIII. We carried out a small number of scenarios with larger state spaces. A larger value of $K_{z}$ shifted the entire release state space to larger captive population sizes; the state space for capturing remained the same. If a population is threatened with extinction, the captive facilities should be filled as quickly as possible and maintained; thus, the larger the captive facilities the larger the number of animals captured. Increasing $K_{w}$ changed neither the capturing nor the release state space. The results were independent of $K_{w}$ because the transition probabilities are independent of $K_{w}$ given $n_{w}<K_{w}$. However, the small value of $K_{w}$ limited the applicability of this implementation of the model to the management of populations that had already declined to very low levels $\left(n_{w}<50\right)$ because the calculated strategy did not cover wild populations larger than this.

\section{Influence of the Per Capita Growth Rate in Captivity, $R_{z}$}

As a baseline case, we assumed that the wild population was decreasing annually by $15 \%$ and that the captive population was increasing annually by 30\% (Figure 1). In general, the lower the population numbers in the wild and in captivity, the higher the proportion of wild animals captured. For example, if the wild population was $\leq 36$ females and there was no captive population, our model suggested transferring the entire wild population into captivity. In some cases, the average number of captured animals exceeded the carrying capacity of the captive population. Although this may seem counterintuitive, it is better to guarantee filling up the captive facilities despite the high risk of losing some animals through lack of space in the captive facilities because the wild population is rapidly approaching extinction. With increasing growth rate in captivity, the region of the state space where capturing was optimal decreased (Figure 2). Because the captive population serves as a safety net, it is best to maintain a large captive population. This is achieved more quickly with high breeding success in captivity; so the initiation of capturing should be delayed until lower abundances of the captive population are reached.

The optimal release strategy was relatively independent of population numbers in the wild. Animals were only released if the captive population was close to its maximum size, and only relatively small numbers were released (between two and six females) (Figure 1). With 


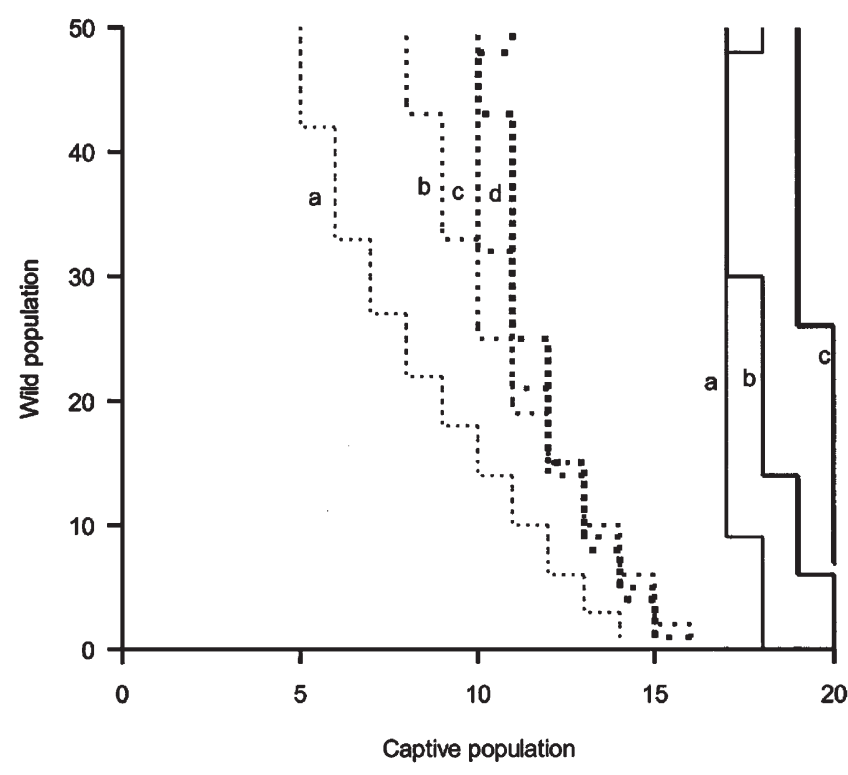

Figure 2. Influence of changing breeding success in captivity on the optimal captive breeding strategies, given that $r_{w}=$ 0.85 . Lines indicate the boundaries between $d>0$ (capturing), $d=0$ (do nothing), and $d<0$ (releasing) (boundaries between the gray and white areas in Figure 1). Dotted lines specify the "capturing" state space boundary and solid lines the "releasing" state space. Letters next to each line indicate the value for the per capita growth rate in captivity: $\mathrm{a}, r_{z}=1.3 ; \mathrm{b}, r_{z}=1.2 ; \mathrm{c}$, $r_{z}=1.1 ; \mathrm{d}, r_{z}=1.0$. If $r_{z}=1.0$, the model suggested that animals should never be released from captivity; consequently, there is no $d$ in the "releasing" state space.

increasing growth rate in captivity, the state space that suggested releasing females increased (Figure 2). If the population in captivity only replaced itself $\left(r_{z}=1.0\right)$, no animals were released. The captive population was an important safety net as long as the population growth rate in captivity was higher than that in the wild, and only surplus females were released into the wild. If $r_{z}=$ 1.0, a surplus in captivity was unlikely. Hence, no animals were released.

As long as the growth rate, $r_{z^{\prime}}$ was the same, the exact combination of the recruitment rate, $\lambda_{z^{\prime}}$ and the mortality rate, $\mu_{z^{\prime}}$ had little influence on the results. The relative values of recruitment and mortality were more important than the absolute values. The exception was in scenarios with $r_{z}=1.2$, where the "capturing" state space was larger for $\mu_{z}=0.2$ (i.e., shifted toward the right) compared with $\mu_{z}=0.04$. This was because the increase in mortality between the two scenarios needed to maintain a growth rate of 1.2 was much larger than for any of the other scenarios.

\section{Influence of the Per Capita Growth Rate in the Wild, $R_{w}$}

Next we assumed that the wild population was growing annually by $10 \%$ and, as before, that the cap-

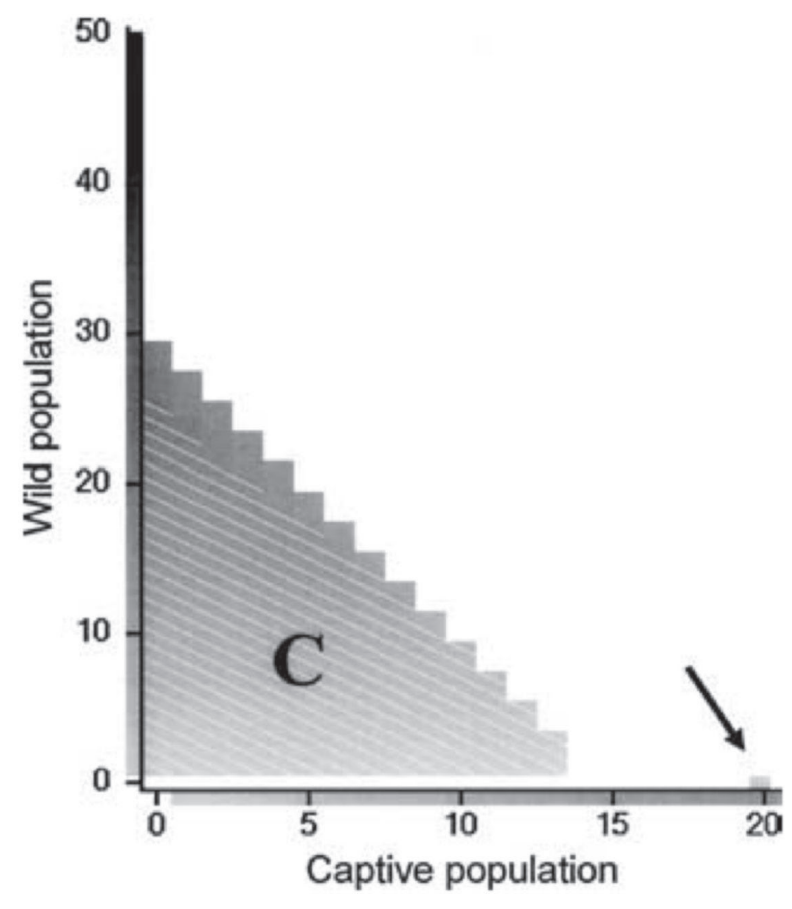

Figure 3. Optimal number of translocated animals as a function of population numbers in the wild and in captivity. The gray-scale intensity is proportional to the number of translocated animals: white, 0; dark gray, 50. Key: C, captures; R, releases; stripes, entire wild population should be captured $(d=$ $n_{w}$ ) (captive population: $\lambda_{z}=1.0, \mu_{z}=0.1, r_{z}=1.3$; wild population: $\left.\lambda_{w}=0.8, \mu_{w}=0.2, r_{w}=1.1\right)$. Arrow indicates the only combination of states where releases take place.

tive population was increasing annually by 30\% (Figure 3). If the wild population was $\leq 29$ females and the captive population was rather small, our model recommended capturing the entire wild population. In contrast to the scenario with a negative growth rate in the wild (Figure 1), the state space where animals were captured was smaller, mainly because the wild population was left alone if the population exceeded 30 females. If the wild population was rather small, the risk of extinction was significant, even if the population was growing. Consequently, it was advantageous to maintain a viable captive population. With decreasing growth rates in the wild, the state space that suggested capturing $\geq 1$ animal increased (Figure 4). There was a trade-off between the risk of individuals dying in the wild and the risk of individuals dying in captivity as a result of the limited maximum size. The worse off the population was in the wild the more the balance shifted in favor of the captive population, resulting in an increasing "capturing" state space with decreasing per capita growth rate in the wild.

The release strategy depended on whether the wild per capita growth rate, $r_{w}$, was $>1$ or $<1$. If the population was decreasing in numbers $\left(r_{w}<1\right)$, the "release" state space decreased with decreasing wild population 
growth rate, $r_{w}$, until no animals were released at $r_{w}<$ 0.85 . At this point the mortality risk in the wild was similar to the mortality risk of the captive population approaching its carrying capacity, and it was better not to release individuals. If the wild population was growing $\left(r_{w}>1\right)$, animals were only released if the captive population had reached its carrying capacity and the wild population was extinct. Not to release excess animals from the zoo was a bit surprising, but if the wild per capita growth rate is $>1$, increasing the number of wild animals does not increase their long-term survival probability because the population will most likely recover from small population sizes on its own, and if the population happens to go extinct, the captive population provides females to recolonize the wild population.

\section{Case Study: Arabian Oryx}

Arabian oryx populations once ranged throughout most of the desert plains of the Arabian Peninsula but became threatened by overhunting and poaching (Marshall \& Spalton 2000). Several captive breeding programs were initiated with the intent of reestablishing oryx into native habitats (Stanley Price 1989; Ostrowski et al. 1998; Spalton et al. 1999). Reintroductions started in 1982, and the wild population increased to 400 animals in 1996. Unfortunately poaching began again and is threatening Arabian oryx with extinction in the wild a second time (Spalton et al. 1999). Oryx populations flourished so well in sanctuaries that Treydte et al. (2001) developed a population viability analysis (PVA) model to determine the optimal number of oryx to eliminate from a sanctuary to minimize the effect of overcrowding.

We parameterized our model with data on Arabian oryx (Oryx leucoryx) from the literature. Here, we summarize the range of vital rates published for this species. Recruitment: Under optimal conditions females give birth to a single calf each year, which has a $75 \%$ (Mace 1988) to $92.5 \%$ (Vie 1996) chance of surviving the first year. Therefore the annual recruitment rate, $\lambda$, is 0.75-0.925, and the sex ratio $f=0.5$ (Mace 1988; Vie 1996; Spalton et al. 1999). Mortality: Annual mortality of adult Arabian oryx in captivity ranges between $4 \%$ and 15\% (Abu Jafar \& Hays-Shahin 1988; Mace 1988). We assumed that the wild mortality rate increases up to $40 \%$ due to poaching (Spalton et al. 1999). Translocation costs: The losses due to capturing and transferring Arabian oryx into captivity and vice versa are small, with mortality ranging between 0 and $5 \%$ (S. Ostrowski, personal communication). As far as we know, fixed costs have not been documented for Arabian oryx. For the sake of parsimony, we assumed that the fixed costs are the same as the variable translocation costs (0.05).

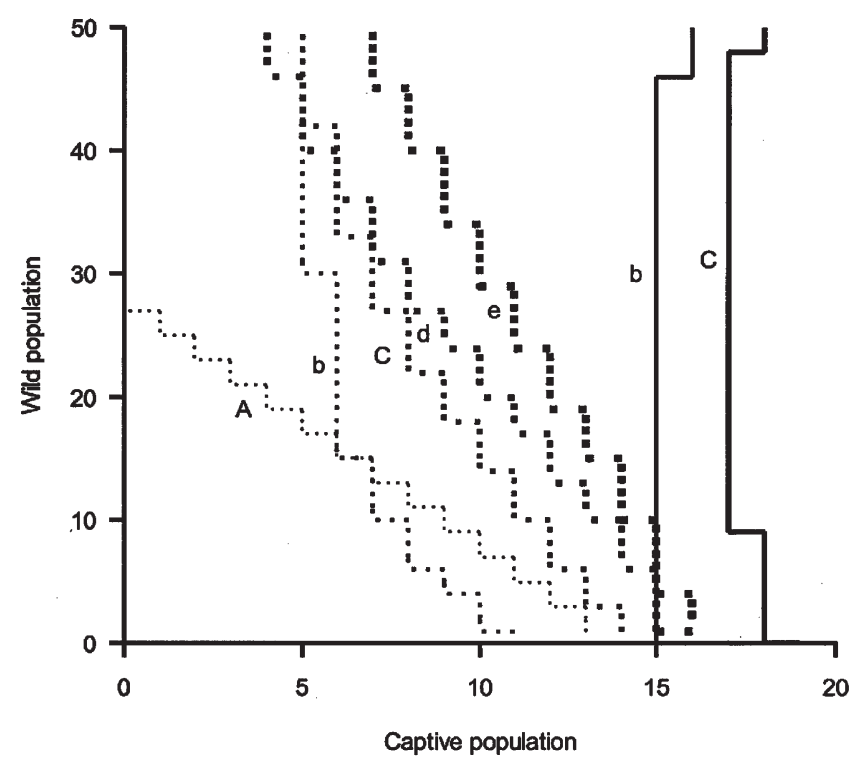

Figure 4. Influence of changing the per capita growth rate of the wild population on optimal captive breeding strategies, given $r_{z}=1.3$. Lines indicate the boundaries between $d>0$ (capturing), $d=0$ (do nothing), and $d<0$ (releasing) (boundaries between the gray and white areas in Figure 3). Dotted lines specify the "capturing" state space boundary and solid lines the "releasing" state space. Letters next to each line indicate the value for the per capita growth rate in the wild: $\mathrm{a}, r_{w}=1.1$; $\mathrm{b}, r_{w}=0.9 ; \mathrm{c}, r_{z}=0.85 ; \mathrm{d}, r_{w}=0.8 ; \mathrm{e}, r_{w}=0.7$. Small and capital letters indicate different recruitment rates in the wild: $\mathrm{A}$ and $\mathrm{C}, \lambda_{w}=0.8 ; \mathrm{b}, \mathrm{d}$, and $\mathrm{e}, \lambda_{w}=0.5$.

For the captive population, we assumed a best-case scenario with a per capita growth rate of $1.3\left(\lambda_{z}=0.5\right.$; $\left.\mu_{z}=0.13\right)$, and for the wild population we assumed a per capita growth rate of $0.85\left(\lambda_{w}=0.4 ; \mu_{w}=0.4\right)$. These per capita growth rates are consistent with population growth rates found in Arabian oryx sanctuaries (Abu Jafar \& Hays-Shahin 1988; Ostrowski et al. 1998; Spalton et al. 1999; Marshall \& Spalton 2000). These parameter combinations are identical to the ones used to calculate the optimal breeding strategies in our first scenario (Figure 1). If the population of Arabian oryx in the wild drops below 36 females, the entire population should be transferred into captivity, and captive-bred individuals should not be released unless the captive facilities are at least $85 \%$ full.

\section{Discussion}

Reintroduction programs have been proposed or carried out for a wide taxonomic range of species. Although many taxonomic groups are suitable for translocations, the majority have been birds and large mammals (Griffith et al. 1989; Wolf et al. 1996, 1998). However, success has been limited (Griffith et al. 1989; Beck et al. 1994), and 
Table 1. Parameter combination for different scenarios in the model for translocations between wild and captive populations.

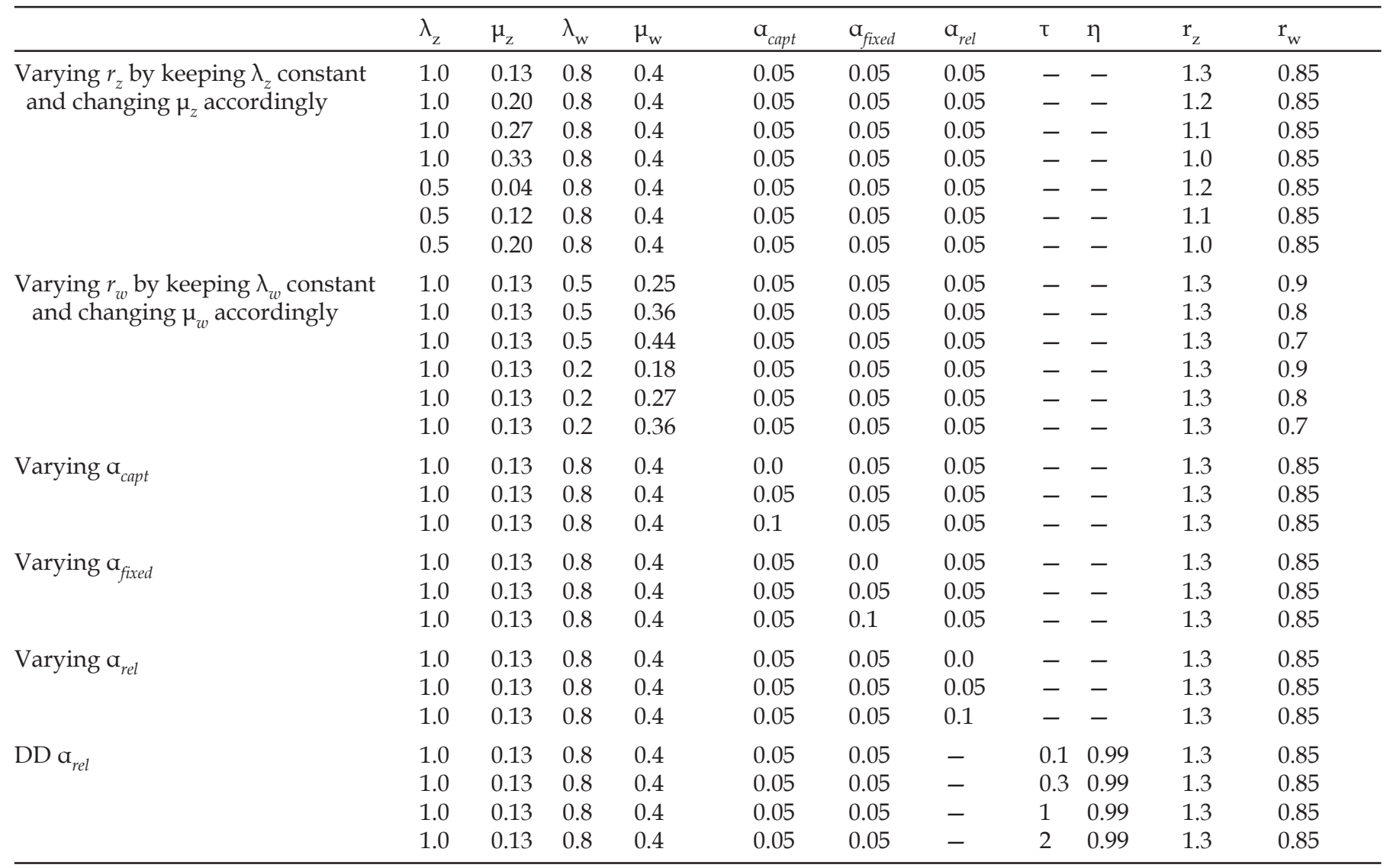

Key: $\mu_{z^{\prime}} \mu_{w^{\prime}}$ mortality rates in captivity or in the wild; $\lambda_{z^{\prime}} \lambda_{w^{\prime}}$ recruitment rate in captivity or in the wild; $r_{z^{\prime}} r_{w^{\prime}}$ per capita growth rate in captivity or in the wild; $a_{\text {cant }} a_{\text {fixed }}, a_{\text {rel }}$ mortality costs for captured individuals, for individuals remaining in the wild, and for released individuals, respectively; $\tau$, rate determining how quickly $a_{r e l}$ decreases with increasing number of released animals; $\eta$, specifies $a_{r e l}$ if only a single animal is released. In all scenarios the carrying capacity for the wild population, $K_{w^{\prime}}$ is 50 , and for the captive population, $K_{z^{\prime}}=20$. If $\lambda_{z}=0.25$, it is impossible to get a growth rate of $r_{z}=1.3$.

we are in need of improved translocation strategies. Critical for the success of translocation programs is the size of translocations between captivity and the wild (Griffith et al. 1989; Veltman et al. 1996; Wolf et al. 1998). It is unlikely that one particular translocation size will always work best; instead, we expect the number of animals translocated to depend on the current number of individuals in the wild $\left(n_{w}\right)$ and in captivity $\left(n_{z}\right)$. The combination of animal numbers in the wild and in captivity may be different each year as a result of demographic change or some management action. We developed an optimization model that finds such state-dependent strategies and recommends unique sequences of optimal management actions over several years.

The maximum population sizes in the model were kept small for practical reasons, but we believe our results have implications for the management of populations that could be larger (i.e., have larger "carrying capacity") but that for whatever reason have been reduced to small numbers. This is because the upper boundary for the wild population can be interpreted as "all population sizes equal or larger than $K_{w}$." This is not strictly correct because the true transition rates out of a state $K_{w}+$ to states $n_{w}<K_{w}$ would incorporate the fact that the population could be far above $K_{w}$, whereas our approximation assumes that transitions are all coming from $K_{w}$. Therefore, our approximation was a somewhat too high of a probability of reaching states below $K_{w}$. However, the effect of this error is small. We compared the 128-year extinction probability from a transition matrix with $K_{w}=50$ with the extinction probability from a transition matrix with $K_{w}=$ 100 , both with $r_{w} \approx 1$. For $n_{w}<40$ they were indistinguishable to the eye, and even at $n_{w}=49$ the difference was only $0.029\left(K_{w}=50\right)$ versus $0.017\left(K_{w}=100\right)$. The approximation was best when population growth was negative and got worse as the population growth rate increased.

Table 2. Parameter combinations to generate different per capita growth rates in the wild $\left(r_{w}\right)$ and in captivity $\left(r_{z}\right)$, given the following recruitment rates: $\lambda_{z}=1.0$ and $\lambda_{w}=0.2$

\begin{tabular}{cccc}
\hline \multicolumn{2}{c}{ Captive population } & \multicolumn{2}{c}{ Wild population } \\
\hline$r_{z}$ & $\mu_{z}$ & $r_{w}$ & $\mu_{w}$ \\
1.0 & 0.334 & 0.7 & 0.363 \\
1.1 & 0.2667 & 0.8 & 0.2728 \\
1.2 & 0.20 & 0.9 & 0.1818 \\
1.3 & 0.1333 & 1.0 & 0.0909 \\
\hline
\end{tabular}


The key determinants of the optimal policy are the per capita growth rates in the wild and in captivity, $r$, which are determined by $\lambda$ and $\mu$. The exact combination of the recruitment rates, $\lambda$, and the mortality rates, $\mu$, have negligible influence on the optimal captive breeding strategies. It is their relative not absolute sizes that matter. This means that time-series analysis can be used to estimate the $r$ values, if such data are available, rather than estimating $\mu$ and $\lambda$ independently.

From these results, we suggest the following general rules of thumb be used as a decision tool for designing translocation programs without running a stochastic programming (SDP) model for every situation, assuming that the zoo population has a better growth rate than the wild population. (1) The frequency of $\left(n_{w}\right.$ $\times n_{z}$ ) combinations suggesting translocations from the wild into captivity and the number of animals involved is higher when the captive population and/or the wild population is smaller. If the wild population is very small ( $<20$ females), the entire wild population is captured, even if the wild population is growing. (2) The frequency of $\left(n_{w} \times n_{z}\right)$ combinations suggesting translocations from captivity into the wild and the number of animals involved is practically independent of the size of the wild population but increases with an increasing captive population.

These rules emphasize that a captive population is critical for the persistence of small populations, assuming that the per capita growth rate in captivity exceeds that in the wild. In fact, if the wild population is small, our model suggests transferring every single wild animal into captivity. Somewhat surprisingly, this holds true even if the per capita growth rate of the wild population is positive. Small populations are inherently in danger of extinction as a result of demographic stochasticity. Thus, the best strategy entails building up population numbers as quickly as possible, which is by propagation in captivity. Once a captive population is established, it is best to maintain it as a safety net and only release animals if the captive population is close to its carrying capacity.

The model does not presently incorporate environmental stochasticity, which would result in fluctuations of vital rates, and consequently growth rates, through time. We also did not incorporate catastrophes, either in the wild or in captivity. This is not to suggest that these processes do not occur or are not important, and they could be included in future versions of the model. However, we would expect that including environmental stochasticity and/or catastrophes in the wild would result in strategies where capturing the entire wild population is recommended for even larger wild population sizes. Including catastrophic mortality in the captive population delays capturing the entire wild population to a time when population sizes are smaller.
Even though the emphasis on a captive population makes intuitive sense, maintaining a captive population as a safety net over many years might not always be practical because of budget constraints. Our model does not include the economic costs of creating and maintaining a captive facility. The costs of captive breeding facilities vary greatly depending on design and species requirements. In some cases, captive facilities consist of only a protective fence against predators, and the animal may pay for itself from visitor revenue. In this case, the maintenance costs could be negligible.

Our model also provides guidance for designing a release program. The key feature of the optimal release scheme is to release small groups of animals over several years. The exact group size varies depending on the abundance of animals in the wild and in captivity. This scheme has three advantages. First, the success of each single release endeavor is of less importance. Sometimes the establishment of released animals is affected by adverse weather conditions, such as droughts. Thus, releasing animals over several years reduces the effect of environmental stochasticity on the success of reintroduction or relocation programs. Second, captive animals multiply at a relatively high rate, supplying the reintroduction program over time with a large number of animals. Third, the state dependency of the optimal management program allows regular adjustment of management actions in response to changes in the population numbers in the wild and in captivity. This way, management actions can be adjusted to improvements in estimates of vital population parameters or the occurrence of catastrophes (e.g., high mortality in a drought year).

Obviously there are different factors that affect the outcome of captive breeding and translocation programs, including choosing release sites within the former historical range of the species (Griffith et al. 1989; Wolf et al. 1998) and with high habitat quality (e.g., Wolf et al. 1998); using a soft release design (e.g., Letty et al. 2000); controlling predators at the release site (Sinclair et al. 1998); training released animals to avoid predators (Griffin et al. 2000); minimizing the risk of transmitting diseases between captive and wild populations (e.g., Griffith et al. 1993; Snyder et al. 1996); and preventing genetic change in captivity (e.g., Ballou 1997; Earnhardt 1999). It is often difficult to change release conditions or foresee the performance of released animals in the wild. Our model allows one to examine scenarios with different growth rates of the wild population. For example, if one expects a low per capita growth rate of the wild population as a result of poor habitat quality of the release site or high predation pressure, the state space identifying optimal releases decreases and the state space suggesting captures increases (see Figure 4). Examining worst- and best-case scenarios allowed us to assess how sensitive optimal release strategies are to different environmental conditions. 


\section{Other Modeling Approaches}

The need for a theoretical framework for translocation strategies is widely recognized (Hodder \& Bullock 1997). Issues that have been addressed theoretically include determining under what circumstances soft release should be favored over hard release; the proportion of the budget that should be allocated to monitoring and the allocation of funds between prerelease and release activities (Haight et al. 2000); the age structure of founder animals (Sarrazin \& Legendre 2000); the optimal size of founder populations and the necessary degree of predator control (Sinclair et al. 1998); and the best distribution of animals between patches (Lubow 1996). No model to date has derived optimal translocation strategies by linking wild and captive populations.

Lubow (1996) also used stochastic dynamic programming (SDP) to find the optimal size and frequency of translocations but only between populations in two reserves. Thus, the parameter values in both populations are identical. He employed a discrete version of the logistic population growth model to describe the population dynamic within reserves. In contrast, we envisioned populations threatened with extinction or reared in captivity, so the dynamics are better described with an exponential growth model, such as a first-order Markov-chain model, with ceiling density dependence. In captivity, animals are kept under "optimal" conditions, which allows animal abundance to increase exponentially. Only when the captive facilities are full does the per capita growth rate equal zero. This sort of ceiling model is often used in software packages for estimating extinction probabilities (e.g., RAMAS, Akcakaya \& Ferson 1990; ALEX, Possingham \& Davies 1995). Despite the differences in the modeling approaches, both models suggest optimal strategies that include frequent movements of a small number of animals between two populations.

Wolf et al. (1998) suggest using population viability analysis (PVA) to determine the minimum viable number of animals to be released. In principle, this population number could also be used as an indicator to instigate conservation measures to "save" the species, such as captive breeding. However, the performance of PVA depends on the availability of high-quality data and the assumption that the distribution of vital rates and population growth rates are constant in the future (Coulson et al. 2001). The optimal release scheme we proposed relies less on high-quality data or accurate predictions of future population performance. Our model is based only on a few parameters, and the general predictions are relatively robust to changes in parameter values.

\section{Acknowledgments}

We thank T. Coulson, E. J. Milner-Gulland, and C. Wilcox, and the other members of the National Center for Ecological
Analysis and Synthesis (NCEAS) working group on managing variability, for useful discussions. We also thank S. Ostrowski for providing information on the Arabian oryx. Comments of three anonymous reviewers for Conservation Biology improved the manuscript. This is a contribution of the University of Nebraska Agricultural Research Division (journal series no. 14363).

\section{References}

Abu Jafar, M. Z., and C. Hays-Shahin. 1988. Reintroduction of the Arabian oryx into Jordan. Pages 35-40 in A. Dixon, and D. Jones, editors. Conservation biology of desert antelopes. Christopher Helm, London.

Akcakaya, H. R., and S. Ferson. 1990. RAMAS/space user manual: Spatially structured population models for conservation biology. Exeter Software, Setauket, New York.

Akcakaya, H. R., M. A. McCarthy, and J. L. Pearce. 1995. Linking landscape data with population viability analysis: management options for the helmeted honeyeater Lichenostomus melanops cassidix. Biological Conservation 73: 169-176.

Ballou, J. D. 1997. Genetic and demographic aspects of animal reintroductions. Supplemento alle Ricerche di Biologia della Selvaggina 27: 75-96.

Balmford, A., G. M. Mace, and N. LeaderWilliams. 1996. Designing the ark: setting priorities for captive breeding. Conservation Biology 10: 719-727.

Beck, B. B., L. G. Rapaport, M. R. Stanley Price, and A. C. Wilson. 1994. Reintroduction of captive-born animals. Pages 287-303 in P. J. S. Olney, G. M. Mace, and A. T. C. Feistner, editors. Creative conservation: Interactive management of wild and captive animals. Chapman and Hall, London.

Bellman, R. 1957. Dynamic programming. Princeton University Press, Princeton, New Jersey.

Coulson, T., G. M. Mace, E. Hudson, and H. Possingham. 2001. The use and abuse of population viability analysis. Trends in Ecology \& Evolution 16: 219-221.

Earnhardt, J. M. 1999. Reintroduction programs: genetic tradeoffs for populations. Animal Conservation 2: 279-286.

Ebenhard, T. 1995. Conservation breeding as a tool for saving animal species from extinction. Trends in Ecology \& Evolution 10: 438-443.

Fischer, J., and D. B. Lindenmayer. 2000. An assessment of the published results of animal relocations. Biological Conservation 96: 1-11.

Griffin, A. S., D. T. Blumstein, and C. Evans. 2000. Training captive-bred or translocated animals to avoid predators. Conservation Biology 14: 1317-1326.

Griffith, B., J. M. Scott, J. W. Carpenter, and C. Reed. 1989. Translocation as a species conservation tool: status and strategy. Science 245: 477-480.

Griffith, B., J. M. Scott, J. W. Carpenter, and C. Reed. 1993. Animal translocations and potential disease transmission. Journal of Zoo and Wildlife Medicine 24: 231-236.

Haight, R. G., K. Ralls, and A. M. Starfield. 2000. Designing species translocation strategies when population growth and future funding are uncertain. Conservation Biology 14: 1298-1307.

Hearne, J. W., and J. Swart. 1991. Optimal translocation strategies for saving the black rhino. Ecological Modelling 59: 279-292. 
Hodder, K. H., and J. M. Bullock. 1997. Translocations of native species in the UK: implications for biodiversity. Journal of Applied Ecology 34: 547-565.

Kleiman, D. G., R. P. Reading, B. J. Miller, T. W. Clark, M. Scott, J. Robinson, R. L. Wallace, R. J. Cabin, and F. Felleman. 2000. Improving the evaluation of conservation programs. Conservation Biology 14: 356-365.

Kostreva, M. M., W. Ogryczak, and D. W. Tonkyn. 1999. Relocation problems arising in conservation biology. Computers $\mathcal{E}$ Mathematics with Applications 37: 135-150.

Letty, J., S. Marchandeau, J. Clobert, and J. Aubineau. 2000. Improving translocation success: an experimental study of anti-stress treatment and release method for wild rabbits. Animal Conservation 3: 211-219.

Lubow, B. C. 1996. Optimal translocation strategies for enhancing stochastic metapopulation viability. Ecological Applications 6: 1268-1280.

Mace, G. M. 1988. The genetic status of the Arabian oryx and the design of cooperative management programmes. Pages 58-74 in A. Dixon, and D. Jones, editors. Conservation biology of desert antelopes. Christopher Helm, London.

MacPhee, R. D. E. 1999. Extinctions in near time: causes, contexts, and consequences. Kluwer Academic and Plenum Publishers, New York.

Maguire, L. A. 1986. Using decision analysis to manage endangered species populations. Journal of Environmental Management 22: 345-360.

Marshall, T. C., and J. A. Spalton. 2000. Simultaneous inbreeding and outbreeding depression in reintroduced Arabian oryx. Animal Conservation 3: 241-248.

Ostrowski, S., E. Bedin, D. M. Lenain, and A. H. Abuzinada. 1998. Ten years of Arabian oryx conservation breeding in Saudi Arabia: achievements and regional perspectives. Oryx 32: 209-222.

Possingham, H. P., and I. Davies. 1995. ALEX: a population viability analysis for spatially structured populations. Biological Conservation 73: 143-150.

Rabinowitz, A. 1995. Helping a species go extinct: the Sumatran rhino in Borneo. Conservation Biology 9: 482-488.

Raiffa, H. 1968. Decision analysis: Introductory lectures on choices under uncertainty. Addison-Wesley, Reading, Massachusetts.

Reed, D. H., and E. H. Bryant. 2001. The relative effects of mutation accumulation versus inbreeding depression on fitness in experimental populations of the housefly. Zoo Biology 20: 145-156.

Sarrazin, F., and S. Legendre. 2000. Demographic approach to releasing adults versus young in reintroductions. Conservation Biology 14: 488-500.

Shabalina, S. A., L. Y. Yampolsky, and A. S. Kondrashov. 1997. Rapid decline of fitness in panmictic populations of Dro- sophila melanogaster maintained under relaxed natural selection. Proceedings of the National Academy of Sciences USA 94: 13034-13039.

Sinclair, A. R. E., R. P. Pech, C. R. Dickman, D. Hik, P. Mahon, and A. E. Newsome. 1998. Predicting effects of predation on conservation of endangered prey. Conservation Biology 12: 564-575.

Snyder, N. F. R., S. R. Derrickson, S. R. Beissinger, J. W. Wiley, T. B. Smith, W. D. Toone, and B. Miller. 1996. Limitations of captive breeding in endangered species recovery. Conservation Biology 10: 338-348.

Southgate, R., and H. Possingham. 1995. Modeling the reintroduction of the greater bilby Macrotis lagotis using the metapopulation model analysis of the likelihood of extinction (Alex). Biological Conservation 73: 151-160.

Spalton, J. A., M. W. Lawrence, and S. A. Brend. 1999. Arabian oryx reintroduction in Oman: Successes and setbacks. Oryx 33: 168-175.

Stanley Price, M. R. 1989. Animal reintroductions: The Arabian oryx in Oman. Cambridge University Press, Cambridge, United Kingdom.

Struhsaker, T. T., and K. S. Siex. 1998. Translocation and introduction of the Zanzibar red colobus monkey: Success and failure with an endangered island endemic. Oryx 32: 277-284.

Treydte, A. C., J. B. Williams, E. Bedin, S. Ostrowski, P. J. Seddon, E. A. Marschall, T. A. Waite, and K. Ismail. 2001. In search of the optimal management strategy for Arabian oryx. Animal Conservation 4: 239-249.

Veltman, C. J., S. Nee, and M. J. Crawley. 1996. Correlates of introduction success in exotic New Zealand birds. The American Naturalist 147: 542-557.

Vie, J. C. 1996. Reproductive biology of captive Arabian oryx (Oryx leucoryx) in Saudi Arabia. Zoo Biology 15: 371-381.

Vitousek, P. M., C. M. Dantonio, L. L. Loope, and R. Westbrooks. 1996. Biological invasions as global environmental change. American Scientist 84: 468-478.

Wolf, C. M., B. Griffith, C. Reed, and S. A. Temple. 1996. Avian and mammalian translocations: update and reanalysis of 1987 survey data. Conservation Biology 10: 1142-1154.

Wolf, C. M., T. Garland, and B. Griffith. 1998. Predictors of avian and mammalian translocation success: reanalysis with phylogenetically independent contrasts. Biological Conservation 86: 243-255.

World Conservation Union (IUCN). 1987. IUCN position statement on translocation of living organisms: introductions, reintroductions and re-stocking. IUCN, Gland, Switzerland.

World Conservation Union (IUCN). 1998. IUCN Species Survival Commission guidelines for re-introductions. IUCN, Gland, Switzerland.

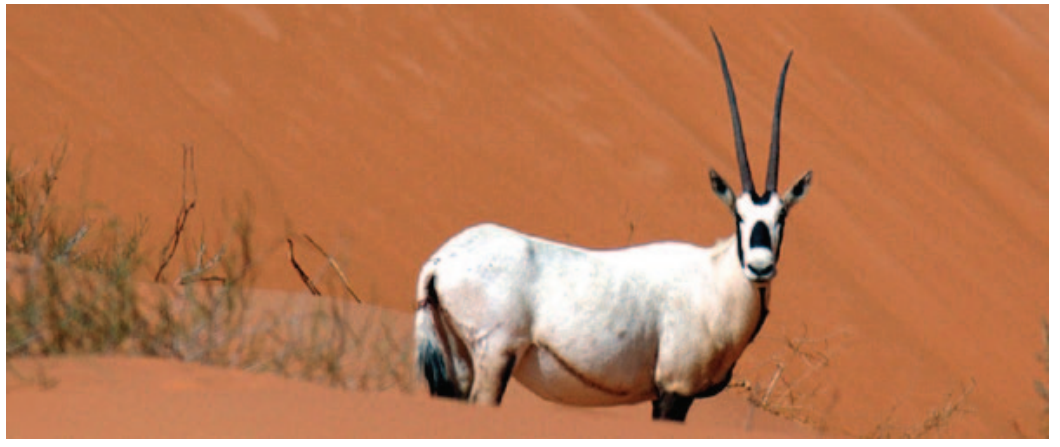

Arabian oryx. Photo: Saudi Wildlife Commission. 